\title{
O debate sobre meio ambiente no jornal Folha de São Paulo entre 1992 e 2008
}

\author{
Emerson Urizzi Cervi* \\ Michele Goulart Massuchin**
}

\section{Resumo}

O tema "meio ambiente" entrou no debate público a partir do momento em que os problemas causados pelas ações do homem na natureza passaram a ser objeto de eventos e conferências. É quando surgem movimentos ambientalistas com o objetivo de defender a causa. Com isso, o assunto também passou a ser recorrente na mídia, principalmente a partir do final do século XX, e ser de interesse público na medida em que se percebeu sua importância na sociedade. Este artigo tem como objetivo analisar de que forma o assunto meio ambiente é abordado pelo jornal Folha de São Paulo entre 1992 e 2008, na tentativa de observar a posição da mídia no debate público a respeito do tema.

Palavras-chave: debate público, meio ambiente, Folha de São Paulo.

\section{Introdução}

Vão é de hoje que se questiona qual é, de fato, o papel da mídia na sociedade. Aruguete (2005) afirma que grande parte das relações dos cidadãos com o mundo é por meio da mídia. Além de que os meios de comunicação possibilitam a criação de uma ima-

\footnotetext{
* Professor do Departamento de Comunicação da Universidade Estadual de Ponta Grossa (UEPG), professor do Departamento de Ciências Sociais da Universidade Federal do Paraná (UFPR - Curitiba) e coordenador do Grupo de Pesquisa em Comunicação, Política e Atores Sociais (UEPG/UFPR). Endereço eletrônico: eucervi@ufpr.br.

*** Mestranda em Ciência Política pela Universidade Federal do Paraná (UFPR - Curitiba), membro do Grupo de Pesquisa em Comunicação e Política da UFPR e bolsista do Programa REUNI. Endereço eletrônico: mimassuchin@hotmail.com.
} 
gem a respeito daquilo que publicam por parte dos leitores, ouvintes e telespectadores. Neste artigo pretende-se mostrar, a partir de alguns autores, como a mídia pode ser importante no debate público. Desde os estudos de McCombs e Shaw, na década de 70, o papel dos meios de comunicação na sociedade tem sido discutido em diversas ocasiões na tentativa de entender como a mídia pode influenciar as discussões na sociedade. Partimos do princípio de que o meio ambiente é um tema de interesse público e alcançou esse espaço na medida em que a mídia, a partir das últimas décadas do século XX passou a dar mais visibilidade para o assunto (SCHMIDT, 2005). Como defenderam os dois autores, McCombs e Shaw, ainda em 1971, a mídia pode não ter o poder de dizer o que pensar, mas é bem sucedida em dizer sobre o que pensar. É a partir do agendamento de temas em coberturas especiais, como as de eleições, por exemplo, que o público escolherá os assuntos que vai debater (McCOMBS \& SHAW, 1972). No entanto, é preciso considerar que os estudos originais dos autores referiam-se a coberturas de temas especiais e não ao agendamento cotidiano. E os autores continuaram nessa mesma linha de estudos, quando nas eleições presidenciais de 1996 nos Estados Unidos constataram que o agendamento conseguia influenciar nas atitudes dos eleitores em relação aos candidatos (KIOUSIS \& McCOMBS, 2004). Além disso, Aruguete (2005) propõe a idéia de que os meios de comunicação possuem o poder de filtrar, midiatizar e enfatizar aquilo que acham importante e também de não dar visibilidade a outros assuntos. A mesma idéia exposta por Habermas (2006) quando fala da mídia como um dos poderes da esfera pública.

O fato do meio ambiente estar presente ou não na mídia significa que passa por esse processo de escolha realizada pelos jornalistas. E na medida em que o tema começou a ganhar espaço nos meios de comunicação no final do século XX, tornou-se assunto importante de debate na sociedade. Obviamente, a mídia também é pautada sobre o que divulgar, escrever e colocar nas páginas de um jornal, por exemplo, pois recebe as informações de grupos de pessoas, os quais também tem interesses na divulgação de determinados assuntos. Porém, ressalta-se que numa espécie 
do jogo de poderes, entre os jornalistas e esses grupos de interesse (políticos, assessorias, empresas, ONGs etc.) é que surgem os assuntos a serem abordados pelo jornal, com objetivo de alcançarem um número maior de pessoas. Isso significa que a mídia faz um papel de mediadora entre esses pequenos grupos e a sociedade para a divulgação das informações, ou seja, é por meio dela que os assuntos, antes restritos a um pequeno grupo, passam a ganhar espaço na sociedade, nos cafés, nas rodas de conversa, entre outros locais.

É o caso do meio ambiente, que antes dos meios de comunicação fazerem o papel de mediadores e divulgadores dos assuntos relacionados a esse tema, era restrito a pequenos grupos. Na medida em que esses grupos conseguem dar visibilidade ao tema nos veículos de comunicação, ele passa a ser assunto de interesse público e debate na sociedade. Assim como política, economia, saúde e educação, o tema meio ambiente também passou a ganhar mais destaque na mídia a partir de um determinado momento, que como colocam Tosi e Villar (2001), pode ser considerado o ano de 1992, devido a realização da Eco-92, no Brasil. Os eventos também são responsáveis em aumentar o agendamento dos meios de comunicação, pois fazem parte da cobertura midiática e contribuem para aumentar a visibilidade e consequentemente o debate na sociedade. $\mathrm{O}$ texto pretende mostrar como o meio ambiente apareceu no jornal Folha de São Paulo a partir de 1992 até 2008, na tentativa de apresentar a sua evolução durante o período, partindo do princípio que essa visibilidade que o tema recebe na mídia, reflete no debate que vai gerar na sociedade, já que é pelos meios de comunicação que a sociedade recebe grande parte das informações que consome no dia-a-dia (ARUGUETE, 2005).

\section{O papel da mídia no debate público a partir da visibilidade dos temas}

Para que um assunto seja considerado apto para tornar-se notícia ele precisa conter algumas características, definida na literatura em jornalismo por valores-notícias. Seriam esses valores- 
-notícias que determinariam o que seria e o que não seria notícia de acordo com o fato em si. Partindo do princípio de que o meio ambiente é um assunto de interesse humano já que está intimamente relacionado com as ações do homem e suas consequiências com a humanidade, ele se enquadra dentro dos valores notícias para que os acontecimentos relacionados ao tema sejam noticiáveis, seja ele um evento, uma enchente, uma descoberta científica etc. Até porque, dependendo do fato, vários dos valores-notícias o enquadram.

Eles são filtros que, de alguma forma, impedem que todos os assuntos que chegam às redações por meio das fontes de informação sejam sempre publicáveis, mas além deles há também os critérios de noticiabilidade internos da redação. A mídia possui seus mecanismos internos que impediriam que os meios de comunicação se tornassem porta-vozes de determinadas assessorias. Assim sendo, de acordo com os elementos jornalísticos, o tema meio ambiente ganha visibilidade no jornal, após passar por esses "filtros". Gans, citado por Franciscato (2002, p. 14) define que a notícia é um produto final desse processo de julgamentos (do fato em si, dos jornalistas, do interesse público etc.) fundados nas regras, padrões, convenções e condicionantes da produção que norteiam as decisões. É por meio desses mecanismos que a mídia possui o poder de indicar sobre o que o público vai discutir, como defende Habermas (2006) quando define a mídia como um dos poderes na esfera pública, justamente por ser a mediação entre os fatos e aquilo que o público vai discutir na sociedade, mas principalmente pelo fato da mídia selecionar os fatos. E é a partir disso que poderemos observar em que medida a mídia contribui para as discussões públicas sobre meio ambiente. Ou seja, na medida em que a mídia fala sobre esse tema, o público possivelmente discutirá sobre ele também. E é dessa forma que entendemos a mídia como importante elemento no debate público a respeito do objeto deste trabalho.

Aruguete (2005) considera que o poder da mídia vai além de interferir sobre que o público vai falar. E a partir disso é que 
tem se estruturado os estudos sobre a agenda da mídia e a agenda pública, pois a partir do momento que o público fala apenas aquilo que a mídia aborda, as agendas acabam coincidindo. É o caso, por exemplo, do tema educação ambiental que aparece em apenas 15 dos 783 textos $(1,9 \%)$ incluídos na pesquisa, sendo que denúncias aparecem em $238(30,4 \%)$ das entradas. A importância dada a um em detrimento de outro pode interferir naquilo que o público vai falar sobre o assunto, enfatizando as denúncias e discutindo menos educação ambiental. $\mathrm{E}$ isso pode ser explicado por Aruguete (2005) quando a autora fala que os meios de comunicação são a principal forma de mediação entre os fatos e os cidadãos que falam sobre ele. Esse processo no qual a mídia possui poderes de planejar a agenda pública, foi o que McCombs e Shaw chamam de "agenda-setting" ainda nos anos 70. Os meios estariam fazendo recortes da realidade e é nessa lógica que este artigo tem como objetivo discutir a importância daquilo que foi encontrado na pesquisa empírica e o que isso significa no debate público, já que a tendência, segundo a hipótese da agenda-setting é que o público deverá debater sobre aquilo que a mídia vai abordar. Sendo assim, a temática ambiental no jornal significará que o tema ganhará visibilidade no debate pública e incidirá na formação da opinião pública dos atores sociais.

Para Aruguete (2005) há três agendas que se relacionam entre si: a agenda midiática, a qual depende da importância que os temas recebem dos meios de comunicação; a agenda pública que leva em consideração a importância que o público dá aos temas; e a agenda política, que diz respeito às ações políticas a respeito de um tema. Sendo que todas se relacionam e se apóiam uma nas outras. A agenda midiática impõe temas sobre o que pensar, com isso a agenda pública se baseia na agenda midiática para considerar quais temas são mais relevantes e devem estar presentes na agenda política posteriormente.

Aruguete (2005) cita Molotch e Lester (1974) para explicar como se distinguem os acontecimentos. Segundo os autores, apenas determinados assuntos aparecem no debate público quando 
estes afetam, delimitam e marcam o tempo e a ordem individual ou coletiva, que seja definido como um problema social, ganhe legitimidade e uma resposta política. Nesse sentido, o tema meio ambiente ganharia visibilidade a partir do momento que é reconhecido neste parâmetro citado pela autora. E isso como já foi dito, aconteceu no final do século, quando se percebeu que os problemas ambientais afetavam a humanidade.

Segundo Fuks (1998), o tema meio ambiente tem espaço propício no Brasil para entrar no debate público. Por ser um assunto que envolve diversos setores da sociedade já deixou de ser um discurso de pequenos grupos para tornar-se objeto de domínio público (FUKS, 1998, p. 01). O assunto passa a ser foco de preocupação da sociedade e nesse processo de construção de preocupações podemos salientar o papel da mídia na publicação do assunto para que ele pudesse ser absorvido pelo público e transformado em debate nas arenas públicas e discutido pelos diversos setores da sociedade, pois como aponta Blanco (2000) os meios de comunicação expressam a opinião pública. Porém, vale ressaltar que a mídia é apenas um componente da esfera pública, onde se dá os diferentes discursos e debates. Há outros atores sociais importantes no debate público, como os políticos, os cientistas, os grupos sociais, mas obviamente com um alcance menor do que da mídia. Segundo Blanco (2000), a imprensa faz parte da esfera pública mais ampla, mas há diversas esferas públicas menores e segmentadas que dão conta dos demais atores.

Para Santiago (2007) que pesquisou a influência da mídia no debate público sobre a lei antitabagismo, há também outros mecanismos que influenciam no processo de construção de sentido, ou seja, não é apenas a mídia, a responsável em emplacar assuntos na arena de debates. Isso significa que a mídia possui poder em levar ao público os assuntos importantes para o debate público, mas que esse processo também pode ser realizado por outras instituições. Mas, a autora ressalta que a mídia ganha um papel de destaque na medida em que ela esta mais presente no dia-a-dia dos cidadãos. 
Os meios de comunicação de massa não são os únicos fóruns para o debate público, mas, uma vez que, constantemente, disponibilizam construções interpretativas da realidade, e são os mais acessíveis em uma sociedade saturada pela mídia, seu conteúdo pode ser tomado como importante indicador das questões gerais de interesse coletivo (SANTIAGO, 2007, P. 07).

Como aponta Habermas (2006), os meios de comunicação têm maior alcance, pois estão baseados nas novas tecnologias de comunicação de massa.

Santiago (2007) fala ainda que o poder da mídia não se dá apenas no fato de mobilizar um grande número de pessoas, como tínhamos colocado até então, mas que a mídia também tem o poder de colocar o assunto em debate de acordo com algumas escolhas do processo de produção, como é o caso da seleção do acontecimento específico, o enquadramento e angulação da notícia, entre outros, os quais McCombs (2009) considera como as fases subsequientes do agendamento. São essas características de produção que dão as condições mais ou menos positivas para a forma e força que o tema ganha no debate público. Isso poderia então, de alguma forma, influenciar na forma com que as pessoas falarão sobre o assunto, de acordo com o enfoque dado pela mídia. Essas escolhas no processo de produção também seriam responsáveis em mobilizar não apenas o debate, mas as ações de outras instituições como o governo. A implantação de uma determinada política pública ambiental local pode estar relacionada com a forma que a mídia a abordou, por exemplo, os problemas causados pelas enchentes na cidade de São Paulo. O viés da matéria é determinado pelo jornalista, ou seja, se o texto jornalístico prioriza o fator econômico, social ou político, por exemplo.

Maia (2002) também fala que há outros atores que contribuem para o debate público além da mídia e que ainda há a idéia de espaço concreto de debate, porém nos dias atuais não é possível tirar o poder que os veículos de comunicação possuem para publicizar as temáticas. No caso do tema meio ambiente, que é o objeto de estudo deste trabalho, os políticos e os cientistas e pes- 
quisadores também são fontes de informação importantes para o debate na esfera pública, porém o papel que a mídia tem em falar sobre o tema e torná-lo público se torna mais expressivo na medida em que alcança uma dimensão maior da sociedade. Por isso a importância do tema estar presente na mídia, afinal só é possível a formação de uma opinião pública a respeito do assunto a partir do momento que as pessoas são informadas a respeito daquilo que precisam saber. Os meios de comunicação representam a base informacional para a tomada de decisão dos indivíduos.

O papel central da mídia no debate público se dá pelo fato de que por meio de uma linguagem comum, os veículos alcançam um número maior de pessoas. Segundo Maia (2002), mesmo que os interlocutores possuam culturas e hábitos diferenciados, os meios de comunicação alcançam esse público por meio dessa linguagem que a autora chama de "comum". Apesar deste aspecto importante a autora situa esse papel da mídia de publicizar os temas para debate na pré-estruturação da esfera pública política, pois o volume informativo presente na cena midiática é maior do que aquilo que de fato será adquirido pelos ouvintes, leitores e telespectadores. Isso leva a crer que, nem tudo aquilo que está na mídia vai se tornar assunto de debate na esfera pública entre os atores sociais e a escolha vai depender daquilo que mais aparece e que mais interessa para esses atores sociais.

Um ponto que pode explicar os tipos específicos de temas ambientais enquadrados pelo jornal é a visibilidade ou invisibilidade (MAIA, 2004) dos atores sociais que aparecem para falar sobre determinados assuntos. Alguns atores, considerados mais fortes ganham mais visibilidade do que os mais fracos (SANTOS, 2003). É o caso daqueles que precisam chamar a atenção da mídia para tornar-se visível e outros por si só já possuem essa visibilidade, que é o caso dos atores políticos. Quando os atores mais fracos e com menor capital simbólico, segundo Blanco (2000), ao ganharem espaço na mídia objetivam a visibilidade pública muito mais do que a visibilidade midiática. 
Os porta-vozes dos movimentos sociais ou membros de redes cívicas, quando têm acesso aos canais da mídia, através de entrevistas, programas televisivos, documentários, buscam introduzir seus temas e questões frente ao público. Assim, as percepções e os argumentos geridos em fóruns de debate crítico dessas associações, muitas vezes longe da visibilidade midiática, ganham acesso à cena de visibilidade pública (MAIA, 2002, p. 15).

Nesse caso, apesar dos atores não estarem sempre na mídia, eles possibilitam, nas poucas vezes que aparecem, a visibilidade do público para com os assuntos que querem publicizar. É o caso das ONGs e movimentos ambientalistas, além dos atores sociais dispersos, a população em geral. Mas destaca-se que em muitos casos, apesar do tema ganhar visibilidade na mídia, os atores que falam sobre ele não servem de fonte para os jornalistas (BLANCO, 2000).

Além de contribuir para a divulgação dos assuntos para fomentar o debate público posteriormente entre os atores políticos e a sociedade civil, a mídia também tem o papel de dar visibilidade àqueles assuntos rotineiros que não são observados no dia-a-dia. E quando estes ganham visibilidade na mídia, passam a fomentar um sistema de accountabilitity - quando o poder público passa a prestar contas das suas ações - mobilizando os atores políticos e também a sociedade civil (MAIA, 2004). Maia (2004) faz um estudo sobre a visibilidade dos problemas de segurança pública a partir da visibilidade que a mídia deu ao sequiestro do ônibus 174 e por meio desse fato percebe-se como a presença do tema na mídia mobilizou presidente, deputados, secretários, entre outros políticos para responder sobre a falta de segurança. No caso do meio ambiente, o fato do jornal dar visibilidade ao assunto, seria possível a implantação de políticas públicas para minimizar os problemas.

E além de fomentar o debate público, a visibilidade que os meios de comunicação dão a determinados assuntos, ajudam a problematizar a questão e conferir um debate a respeito do tema por todos os setores da sociedade. Dizendo de fato que houve participação da sociedade e a formação da opinião pública por meio da informação do público. Esse fato pode ser verificado no estudo 
de Santiago (2007) a respeito da lei antitabagismo e o destaque que $o$ assunto recebeu na sociedade.

No próximo tópico apresenta-se a análise dos dados encontrados no jornal Folha de SP sobre o tema ambiental. A partir dessas informações é possível perceber o quanto o tema meio ambiente aparece no jornal e de que forma ele aparece (quais os temas específicos priorizados pelos jornalistas).

\section{Como o jornal Folha de São Paulo pauta o meio ambiente: uma análise de 1992 a 2008}

Nesta parte do artigo são apresentados os dados referentes à pesquisa empírica que observou como o tema meio ambiente apareceu no jornal de 1992 a 2008 em seus diversos aspectos, desde a visibilidade e espaço ocupado nas páginas até os diferentes assuntos abordados. A pesquisa com o Jornal Folha de SP foi feita pela observação quantitativa e o levantamento dos dados foi por amostragem, a qual é chamada por Bauer (2002) de amostra por semana composta ${ }^{1}$. A pesquisa observou 442 edições no período, onde foram encontrados 783 textos jornalísticos sobre a temática ambiental. Os textos foram analisados a partir de três categorias específicas: ambiental, geral e específico. Esse tipo de pesquisa tem por objetivo traçar um mapa geral da cobertura da mídia, buscando, empiricamente, reconhecer os resultados dos processos de newsmaking. Ela não é adequada para a verificação dos efeitos nas notícias no público. Também não serve como inferência sobre o processo de produção e das escolhas feitas pelos jornalistas nas salas de redações. Aqui, pretende-se medir o resultado da produção jornalística a partir do que é publicado nas páginas dos jornais.

\footnotetext{
1 Esse tipo de amostra, denominada por Bauer (2002) como amostra por semana composta é utilizada no trabalho da seguinte forma. Sorteia-se um dia da semana para iniciar a análise e a cada semana seguinte, analisa-se o dia da semana seguinte, como por exemplo: Na primeira semana observa a quarta-feira, na segunda semana a quinta-feira, na terceira semana à sexta feira e assim sucessivamente em todo o período de análise. Esse tipo de amostra permite uma maior segurança quando a proximidade dos dados coletados com a realidade do veículo.
} 
Para tanto, estabelece, a partir de conceitos teóricos, as variáveis empíricas que são usadas para extrair das páginas dos jornais informações necessárias para produzir conclusões, na medida do possível, objetivas, ou seja, tirada a partir daquilo que se pode conhecer como resultado da produção jornalística. Para tanto, a unidade de análise é o texto publicado que contenha alguma relação com a temática 'meio ambiente'. A respeito desses textos são extraídas informações que buscam identificar as características internas deles e, a partir de então, verificar a existência de padrões e/ou preferências explicitadas na produção dos jornalistas.

Dentre as variáveis pesquisadas e apresentadas aqui, o 'tema geral' busca identificar o teor de cada texto, ou seja, sem levar em conta o tema específico da matéria, identificar se a idéia do texto é apresentar uma discussão/política pública sobre o tema, uma denúncia, resultado de pesquisas, eventos ou educação ambiental. Além da categoria 'outro' que pode englobar as notícias não contempladas pelas outras categorias. Além da variável 'tema geral', há outras duas que trabalham com o tema específico. É o caso de 'tema ambiental' e 'tema aberto'. A primeira foi construída a partir de leituras dos três documentos que resultaram das conferências da ONU. O 'tema ambiental' é composto de três categorias: 'poluição', 'desenvolvimento sustentável' e 'mudanças climáticas'. Cada uma delas, nesta ordem, representa o tema mais relevante de cada conferência, e se não o mais relevante, o que se desencadeou a partir do evento. A variável 'tema aberto' tem como objetivo identificar os temas específicos trabalhados pelo veículo. A idéia inicial era já estabelecê-los por meio de códigos, mas como são inúmeros os assuntos e dificilmente seria possível colocar no papel sem antes fazer a análise, optou-se em descrever o tema específico e depois apresentar o panorama do que foi encontrado.

Para tentar explicar de que forma o veículo aborda os diferentes assuntos relacionados ao tema central desta pesquisa, apresentamos na Tabela 1 a forma como as três discussões centrais das conferências realizadas pela ONU estiveram presentes no jornal. Mas, ressalta-se que foram coletadas 783 matérias sobre o tema 
'meio ambiente', o que significa que apesar dos problemas relacionados à produção jornalística detectados nos textos (esta análise foi realizada em trabalho de conclusão de curso que observou outras variáveis, além do tema), percebe-se que o tema apareceu na mídia durante todo o período, o que significa que é considerado pelos meios de comunicação um tema relevante e de interesse público, que certamente será debate na esfera pública e que também poderá aparecer na agenda política, nas formas de políticas públicas, por exemplo.

Tabela 1 - Número de vezes que os temas aparecem durante o período

\begin{tabular}{|l|c|c|}
\hline Tema Ambiental & Frequência & $\%$ \\
\hline Poluição Estocolmo-72 & 180 & 23,0 \\
\hline Desenvolvimento Sustentável_Rio 92 & 368 & 47,0 \\
\hline Mudanças climáticas Rio+10 & 235 & 30,0 \\
\hline Total & 783 & 100,0 \\
\hline
\end{tabular}

Fonte: Autores.

De acordo com Tabela 1, é possível perceber que o tema 'Desenvolvimento Sustentável', que foi a principal discussão durante a ECO-92, é também o que mais apareceu durante os 17 anos analisados (47\% das entradas). 'Poluição', por exemplo, não chega nem a metade do número de entradas sobre 'Desenvolvimento Sustentável' (180 de poluição contra 368 de desenvolvimento sustentável). 'Mudanças climáticas' ficaram com 30\% das entradas totais do período (235 entradas). Outro dado que ajuda a compreender como esses temas aparecem no jornal, e se de fato, os eventos tiveram alguma relevância para influenciar na discussão, é mostrado no Gráfico 1 a quantidade de entradas desses três assuntos ao longo do tempo. 
Gráfico 1 - Distribuição dos temas ao longo dos anos



Fonte: Autores.

É possível perceber que, apesar dos eventos terem os três temas como principal discussão em cada um deles, as conferências não influenciaram para aumentar a cobertura do veículo sobre eles. As informações do gráfico mostram que não há relação entre a realização dos eventos e o aumento de entradas sobre os temas no jornal, pelo menos em 2002. Nesse ano, a conferência não surtiu efeito nem para aumentar a produção sobre 'desenvolvimento sustável', que foi retomado durante a conferência, nem das 'mudanças climáticas' que era o assunto novo que foi discutido. Dessa forma conclui-se que em 2002 o evento não foi considerado como relevante pelo jornal, pelo menos no que diz respeito a produção final de notícias. 
O 'desenvolvimento sustentável', além de ter o maior número de entradas durante todo o período é aquele que possui mais entradas em cada ano (exceto 1994, 1996 1998). O que pode ajudar a explicar os três períodos de pico (1992, 2000 e 2008) é que no primeiro caso houve a realização da ECO-92, a qual discutiu o tema, no segundo, pelo aumento de notícias sobre legislação, novas tecnologias e discussão/políticas públicas e no terceiro pelo fato de ser o ano em que teve o maior número de textos coletados, fazendo com que os três tivessem uma elevação no período. Relacionando com os outros dois assuntos, o 'desenvolvimento sustentável' é o único em que o aumento do número de notícias pode ter relação com o evento no qual ele foi discutido (ECO-92, em 1992, no Rio de Janeiro). Além disso, ele se manteve durante quase todo o período pesquisado liderando o número de textos no jornal, perdendo apenas em 1994, 1996 e 1998 para os outros dois. Pelos dados observados, percebe-se que o jornal deu mais visibilidade para o tema 'desenvolvimento sustentável', e partindo dos conceitos da hipótese da agenda setting, esse também foi o tema posteriormente mais discutido na esfera pública e também na agenda política, resultando em políticas públicas, campanhas, programas e ações específicas para o desenvolvimento sustentável no país (tema que aparece na variável 'tema geral').

O tema 'mudanças climáticas', foi o assunto novo na RIO +10 , em Johanesburgo, na África do Sul, mas o Gráfico 1 mostra que o evento não teve força para aumentar o número de notícias sobre o tema na Folha de São Paulo. O evento aconteceu em 2002, mas 'mudanças climáticas', além de já ser pauta desde o início da pesquisa, não teve aumento significativo no ano em que aconteceu o evento. Vale ressaltar que, em 2002, o tema teve menos entradas do que nos anos anteriores (2000 e 2001). Nos anos seguintes ao evento, em 2004 e 2005, foi percebido um pequeno aumento, mas mesmo assim não foi tão relevante, pois em 2001 continuou havendo um número maior de entradas e nos anos de 2003, 2006 e 2007, houve uma queda. Isso mostra que o tema oscila durante todo o período e tem seu pico em 2008, o que está relacionado com o aumento no número de entradas naquele ano. Isso pode 
ser explicado pelo valor notícia proximidade, pois A Eco-92 foi no Brasil, mas o Encontro de 2002 foi em Joanesburgo. Como os jornalistas possuem critérios de noticiabilidade, os fatos para se tornar notícia precisam obter algum desses critérios para ser noticiável.

Já o tema 'poluição', que foi uma das discussões centrais da Conferência de Estocolmo (1972), aparece em mais apenas a partir do ano 2000. Isso significa que o assunto também não é contínuo no jornal, pois aparece em maior proporção apenas nos últimos anos da pesquisa. Apesar de a poluição ser um assunto recorrente no planeta, o tema não é pauta frequiente no jornal e é o que menos aparece dos três. A Tabela 2 mostra a frequiência dos temas ao longo dos anos de forma mais clara complementando as informações do Gráfico 1.

Tabela 2 - Frequência dos temas ao longo dos anos

\begin{tabular}{|c|c|c|c|c|c|c|c|c|}
\hline \multirow{2}{*}{$\begin{array}{l}\text { Ano } \\
1992\end{array}$} & \multicolumn{2}{|c|}{ Poluição } & \multicolumn{2}{|c|}{$\begin{array}{c}\text { Desenvolvimento } \\
\text { Sustentável }\end{array}$} & \multicolumn{2}{|c|}{$\begin{array}{l}\text { Mudança } \\
\text { Climática }\end{array}$} & \multicolumn{2}{|c|}{ Total } \\
\hline & $3,3 \%$ & 6 & $13,3 \%$ & 49 & $6,4 \%$ & 15 & $8,9 \%$ & 70 \\
\hline 1993 & $6 \%$ & 1 & $2,2 \%$ & 8 & $1,7 \%$ & 4 & $1,7 \%$ & 13 \\
\hline 1994 & $5,0 \%$ & 9 & $1,6 \%$ & 6 & $8,5 \%$ & 20 & $4,5 \%$ & 35 \\
\hline 1995 & $6,7 \%$ & 12 & $3,8 \%$ & 14 & $5,1 \%$ & 12 & $4,9 \%$ & 38 \\
\hline 1996 & $5,0 \%$ & 9 & $2,2 \%$ & 8 & $5,5 \%$ & 13 & $3,8 \%$ & 30 \\
\hline 1997 & $1,7 \%$ & 3 & $5,2 \%$ & 19 & $7,7 \%$ & 18 & $5,1 \%$ & 40 \\
\hline 1998 & $5,6 \%$ & 10 & $1,6 \%$ & 6 & $7,7 \%$ & 18 & $4,3 \%$ & 34 \\
\hline 1999 & $2,2 \%$ & 4 & $2,4 \%$ & 9 & $2,1 \%$ & 5 & $2,3 \%$ & 18 \\
\hline 2000 & $9,4 \%$ & 17 & $9,8 \%$ & 36 & $5,1 \%$ & 12 & $8,3 \%$ & 65 \\
\hline 2001 & $10,0 \%$ & 18 & $6,3 \%$ & 23 & $8,1 \%$ & 19 & $7,7 \%$ & 60 \\
\hline 2002 & $6,1 \%$ & 11 & $1,9 \%$ & 7 & $4,7 \%$ & 11 & $3,7 \%$ & 29 \\
\hline 2003 & $9,4 \%$ & 17 & $5,4 \%$ & 20 & $4,3 \%$ & 10 & $6,0 \%$ & 47 \\
\hline 2004 & $3,3 \%$ & 6 & $7,3 \%$ & 27 & $5,5 \%$ & 13 & $5,9 \%$ & 46 \\
\hline 2005 & $6,1 \%$ & 11 & $7,1 \%$ & 26 & $7,2 \%$ & 17 & $6,9 \%$ & 54 \\
\hline 2006 & $5,0 \%$ & 9 & $8,4 \%$ & 31 & $3,4 \%$ & 8 & $6,1 \%$ & 48 \\
\hline 2007 & $7,2 \%$ & 13 & $6,8 \%$ & 25 & $5,1 \%$ & 12 & $6,4 \%$ & 50 \\
\hline 2008 & $13,3 \%$ & 24 & $14,7 \%$ & 54 & $11,9 \%$ & 28 & $13,5 \%$ & 106 \\
\hline Total & $100,0 \%$ & 180 & $100,0 \%$ & 368 & $100,0 \%$ & 235 & $100,0 \%$ & 783 \\
\hline
\end{tabular}

Fonte: Autores. 
É possível identificar que no ano de 2008 houve um aumento significativo de todos os temas, já que foi o ano em que teve maior incidência de entradas (13,5\% do total) e como mostram os dados da Tabela 2, todos os assuntos também tiveram maior número de matérias, comparando com períodos anteriores. Além disso, essa tabela apresenta os pontos de picos semelhantes àqueles identificados na Tabela 1 e Gráfico 1, sobre a maior utilização do espaço para o tema dentro do jornal (em 1992, 2000, 2001 e 2008).

Como já foi observado, a Conferência de 2002 não contribuiu para aumentar a produção sobre mudanças climáticas e desenvolvimento sustentável. E com os dados da Tabela 2 podemos ver nos valores totais de entradas, que em 2002 também não há elevação quanto ao número total de textos, diferente de 1992, em que o evento foi responsável pelo aumento da produção naquele ano. $\mathrm{O}$ que pode ajudar a explicar essa diferença observada entre a atuação de um evento e outro na produção do jornal é a questão geográfica. A ECO-92 aconteceu no Rio de Janeiro, o que pode ser uma das influências para a maior produção do veículo já que era na área de abrangência do veículo. $\mathrm{O}$ evento instigou as discussões sobre o tema, fazendo com que o jornal produzisse mais sobre aquele assunto. Porém isso não ocorre quando acontece a Rio +10 , em Johanesburgo. Apesar da tendência da globalização, do uso de agências de notícias e da própria Internet, o jornalismo ainda tem como valor notícia a proximidade, por isso que um evento teve influência na produção e o outro não.

Além do tema ambiental, a análise apresenta outra variável que discute os assuntos apresentados pelo veículo. Porém, esta outra está relacionada com o tema geral da matéria (políticas/discussão pública, denúncia, resultado de pesquisa, eventos, educação ambiental e outro). A Tabela 3 mostra o número de entradas de cada uma das categorias durante todo o período analisado. 
Tabela 3 - Números de entradas de cada tema durante o período

\begin{tabular}{|l|c|c|}
\hline Tema Geral & Frequência & $\%$ \\
\hline Políticas públicas em meio ambiente & 238 & 30,4 \\
\hline Denúncia & 372 & 47,5 \\
\hline Resultado de pesquisas & 93 & 11,9 \\
\hline Eventos & 61 & 7,8 \\
\hline Educação ambiental & 15 & 1,9 \\
\hline Outro & 4 & 0,5 \\
\hline Total & 783 & 100,0 \\
\hline
\end{tabular}

Fonte: Autores.

Por meio desta tabela percebe-se que alguns assuntos específicos ganham mais espaço do que outros no jornal, seja pelo seu valor notícia, pelas decisões da redação ou pelo agendamento feito pelas próprias fontes de informação. 'Denúncia' é o tema mais recorrente durante todo o período analisado, chegando a $47,5 \%$ dos textos coletados, possivelmente por concentrar os critérios de noticiabilidade. Outro tema que é bastante visível no jornal e ocupa a segunda colocação entre os que mais aparecem é 'discussão e política pública em meio ambiente'. Assunto este que é resultado das ações resultantes da agenda pública e que ao mesmo tempo faz parte da agenda da mídia por ser de interesse público, por serem ações do poder público em benefício da sociedade. Essa categoria ficou com $30,4 \%$ das entradas. Tal resultado pode estar relacionado com a facilidade na cobertura, já que quando se trata de políticas públicas, na maior parte dos casos, um dos entrevistados será fonte oficial (ministro, deputado etc.) e como há preferência do veículo por esse tipo de fontes (como veremos mais à frente) facilitaria a cobertura. 
'Resultados de pesquisa' ocupa a terceira colocação com $11,9 \%$ e 'eventos' fica com 7,8\%. Já 'educação ambiental' e 'outro' são quase insignificantes perto do número de entradas (783) obtidas na pesquisa. 'Educação ambiental' possui 15 entradas e 'outro', apenas quatro entradas. Observam-se aqui como alguns assuntos aparecem menos em relação aos outros, aparecendo poucas vezes para suscitar o debate e compor a agenda pública, sendo que no caso do debate sobre o tema 'meio ambiente' esse assunto seria importante na medida em que estaria relacionado com as ações do homem. Assim como os meios são capazes de propor sobre o que pensar, e consequentemente discutir na esfera pública, também tem o poder de omitir. Nessa argumentação, entra outra questão importante que é o valor notícia "atualidade/novidade", ou seja, aquilo que é novo, que acontece no dia-a-dia e tem que ser noticiado. Isso também ajuda a explicar o grande número de entradas de 'denúncia' (que também é o tema que mais aparece na capa) e a pequena quantidade sobre 'educação ambiental', já que este último não é um tema factual, no sentido de ter que ser noticiado naquele dia senão perderá seu valor como notícia. Como o espaço do jornal é restrito, priorizam-se então as notícias mais urgentes em serem noticiadas e que chamam mais a atenção. Como o tema meio ambiente ainda não é permanente no jornal e depende de acontecimentos para ganhar visibilidade, não há muitas notícias não-factuais e de contextualização, como geralmente são aquelas sobre educação ambiental, que englobam coleta seletiva ou projetos educacionais, por exemplo. A Tabela 4 mostra a entrada que os temas obtiveram em cada ano. 
Tabela 4 - Entrada dos temas gerais ao longo do período analisado

\begin{tabular}{|c|c|c|c|c|c|c|c|c|c|c|c|c|c|c|c|}
\hline Ano & \multicolumn{2}{|c|}{$\begin{array}{c}\text { Discussão/ } \\
\text { Políticas } \\
\text { públicas }\end{array}$} & \multicolumn{2}{|c|}{ Denúncia } & \multicolumn{2}{c|}{$\begin{array}{c}\text { Resultados } \\
\text { de pesquisas }\end{array}$} & \multicolumn{2}{|c|}{ Eventos } & \multicolumn{2}{|c|}{$\begin{array}{c}\text { Educação } \\
\text { ambiental }\end{array}$} & \multicolumn{2}{|c|}{ Outro } & \multicolumn{2}{|c|}{ Total } \\
\hline 1992 & $4,6 \%$ & 11 & $5,4 \%$ & 20 & $4,3 \%$ & 4 & $54,1 \%$ & 33 & $13,3 \%$ & 2 & $0,0 \%$ & 0 & $8,9 \%$ & 70 \\
\hline 1993 & $1,7 \%$ & 4 & $1,9 \%$ & 7 & $1,1 \%$ & 1 & $1,6 \%$ & 1 & $0,0 \%$ & 0 & $0,0 \%$ & 0 & $1,7 \%$ & 13 \\
\hline 1994 & $2,1 \%$ & 5 & $6,2 \%$ & 23 & $4,3 \%$ & 4 & $3,3 \%$ & 2 & $6,7 \%$ & 1 & $0,0 \%$ & 0 & $4,5 \%$ & 35 \\
\hline 1995 & $1,7 \%$ & 4 & $5,9 \%$ & 22 & $8,6 \%$ & 8 & $1,6 \%$ & 1 & $6,7 \%$ & 1 & $50,0 \%$ & 2 & $4,9 \%$ & 38 \\
\hline 1996 & $2,5 \%$ & 6 & $4,8 \%$ & 18 & $1,1 \%$ & 1 & $0,0 \%$ & 0 & $33,3 \%$ & 5 & $0,0 \%$ & 0 & $3,8 \%$ & 30 \\
\hline 1997 & $4,6 \%$ & 11 & $4,6 \%$ & 17 & $2,2 \%$ & 2 & $14,8 \%$ & 9 & $6,7 \%$ & 1 & $0,0 \%$ & 0 & $5,1 \%$ & 40 \\
\hline 1998 & $3,4 \%$ & 8 & $6,7 \%$ & 25 & $0,0 \%$ & 0 & $0,0 \%$ & 0 & $6,7 \%$ & 1 & $0,0 \%$ & 0 & $4,3 \%$ & 34 \\
\hline 1999 & $2,5 \%$ & 6 & $3,0 \%$ & 11 & $0,0 \%$ & 0 &, $0 \%$ & 0 & $6,7 \%$ & 1 & $0,0 \%$ & 0 & $2,3 \%$ & 18 \\
\hline 2000 & $10,5 \%$ & 25 & $8,3 \%$ & 31 & $8,6 \%$ & 8 & $1,6 \%$ & 1 &, $0 \%$ & 0 & $0,0 \%$ & 0 & $8,3 \%$ & 65 \\
\hline 2001 & $8,4 \%$ & 20 & $8,9 \%$ & 33 & $5,4 \%$ & 5 &, $0 \%$ & 0 & $13,3 \%$ & 2 & $0,0 \%$ & 0 & $7,7 \%$ & 60 \\
\hline 2002 & $3,4 \%$ & 8 & $3,8 \%$ & 14 & $4,3 \%$ & 4 & $4,9 \%$ & 3 & $0,0 \%$ & 0 & $0,0 \%$ & 0 & $3,7 \%$ & 29 \\
\hline 2003 & $6,3 \%$ & 15 & $6,7 \%$ & 25 & $7,5 \%$ & 7 & $1,6 \%$ & 1 & $0,0 \%$ & 0 & $0,0 \%$ & 0 & $6,1 \%$ & 48 \\
\hline 2004 & $6,3 \%$ & 15 & $3,8 \%$ & 14 & $12,9 \%$ & 12 & $8,2 \%$ & 5 & $0,0 \%$ & 0 & $0,0 \%$ & 0 & $5,9 \%$ & 46 \\
\hline 2005 & $8,4 \%$ & 20 & $6,7 \%$ & 25 & $9,7 \%$ & 9 &, $0 \%$ & 0 & $0,0 \%$ & 0 & $0,0 \%$ & 0 & $6,9 \%$ & 54 \\
\hline 2006 & $7,6 \%$ & 18 & $5,6 \%$ & 21 & $9,7 \%$ & 9 &, $0 \%$ & 0 & $0,0 \%$ & 0 & $0,0 \%$ & 0 & $6,1 \%$ & 48 \\
\hline 2007 & $9,2 \%$ & 22 & $5,4 \%$ & 20 & $4,3 \%$ & 4 & $4,9 \%$ & 3 & $0,0 \%$ & 0 & $0,0 \%$ & 0 & $6,3 \%$ & 49 \\
\hline 2008 & $16,8 \%$ & 40 & $12,4 \%$ & 46 & $16,1 \%$ & 15 & $3,3 \%$ & 2 & $6,7 \%$ & 1 & $50,0 \%$ & 2 & $13,5 \%$ & 106 \\
\hline Total & $100 \%$ & 238 & $100 \%$ & 372 & $100 \%$ & 93 & $100 \%$ & 61 & $100 \%$ & 15 & $100 \%$ & 4 & $100 \%$ & 783 \\
\hline
\end{tabular}

Fonte: Autores.

A tabela apresenta as entradas dos temas em cada ano. Apesar de a pesquisa ter catalogado 61 notícias sobre 'eventos', 54,1\% delas estão compactadas no ano de 1992, quando aconteceu a Eco-92, e são apenas sobre esse evento. Já textos sobre a Rio +5 e Rio +10, outros dois eventos importantes na área de meio ambiente, apareceram cinco e duas vezes, respectivamente. Ou seja, os demais eventos que aconteceram, até mesmo eventos menores, não receberam espaço no jornal tanto quanto a Eco-92, que resultou num aumento da produção naquele ano. Essas informações mostram que o aumento do número de notícias, em 1992, diz respeito a eventos, mas, além disso, essa diferença entre a cobertura 
de um acontecimento e outro, leva novamente à discussão sobre a importância do valor notícia proximidade, pois como os outros eventos não aconteceram no Brasil, consequientemente, a cobertura feita pelo jornal foi menor, explicando então o número reduzido de textos.

Percebe-se ainda que o tema 'políticas públicas' concentra-se mais a partir do ano 2000 até 2008 e nos anos anteriores a frequiência de textos é bem menor. $76,1 \%$ das entradas se encontram nos últimos oito anos da pesquisa. Esse dado mostra que as discussões públicas e políticas sobre meio ambiente ganharam mais espaço no veículo a partir desse período, o que pode contribuir para o aumento do debate a respeito desse assunto na sociedade. Além de estar relacionado também com o aumento do número de textos sobre o tema meio ambiente, que se dá também com maior relevância neste período. Já 'denúncia' apresenta mais estabilidade no número de entradas ao longo do período, tendo um período de pico em 2000 e 2001 e em 2008, o que pode estar relacionado com assuntos factuais do período e em 2008 mais especificamente, está relacionado também com o aumento no número total de textos coletados.

O tema 'resultados de pesquisa' apresenta-se oscilante na década de 90, apresentando um leve aumento a partir de 2000 , tendo seu pico em 2004 e 2008. Neste último ano, não foi constatado nenhum elemento diferenciado, mas em 2004 houve uma atenção maior para as pesquisas sobre efeito estufa e mudanças climáticas. Ao contrário dos demais assuntos, 'educação ambiental', além de ser quase insignificante em relação aos demais, apresenta-se concentrado na década de 90, sendo que em 1996 apareceram 5 dos 15 textos coletados.

Para exemplificar, é possível perceber na Tabela 5 que assim como o número de entradas, o espaço ocupado pelas notícias segue a mesma sequiência da tabela acima, dada pelo número de entrada de cada categoria. 
Tabela 5 - Espaço ocupado $\mathrm{em}^{\mathrm{cm}^{2}}$ por cada tema no jornal

\begin{tabular}{|l|c|c|}
\hline Tema Geral & $\mathbf{N}^{\mathbf{0}}$ de Entradas & $\mathbf{C m}^{\mathbf{2}}$ \\
\hline Políticas públicas em meio ambiente & 238 & $75.144,75$ \\
\hline Denúncia & 372 & $110.655,05$ \\
\hline Resultado de pesquisas & 93 & $30.862,75$ \\
\hline Eventos & 61 & $13.554,75$ \\
\hline Educação ambiental & 15 & $3.369,50$ \\
\hline Outro & 4 & 900,25 \\
\hline Total & 783 & $234.487,05$ \\
\hline
\end{tabular}

Fonte: Autores.

Como se pode observar, 'denúncia' além de ser o tema que obteve maior número de entradas, também é o que utiliza maior espaço no jornal, com $110.655,05 \mathrm{~cm}^{2}$. O segundo colocado que também ocupa grande parte do espaço é 'discussão/políticas públicas em meio ambiente', com $75.144,75 \mathrm{~cm}^{2}$. 'Resultados de pesquisa' fica em terceiro lugar, com $30.862,75 \mathrm{~cm}^{2} \mathrm{e}$ 'eventos' em quarto com 13.554,75. Esses dados mostram que assim como os temas se colocam com relação ao número de entradas, continuam quando observado o espaço utilizado. 'Educação ambiental', além de ter o segundo menor número de entradas, também aparece na mesma situação se observar o espaço ocupado.

Outra forma de observar o espaço e a visibilidade de cada tema no jornal Folha de São Paulo é por meio da Tabela 6, que trabalha com o tamanho categórico (baixo, médio e alto), obtido pela Fórmula de Sturges ${ }^{2}$ e que ajuda a perceber como a quantidade de textos de tamanho baixo está acima da média da categoria. Como já se sabe que o tamanho baixo é predominante, a observação é baseada na média obtida em cada um dos tamanhos e nos valores de cada um dos temas, observando se estão abaixo ou acima da média geral. Aqui se percebe que além de alguns temas serem praticamente "omitidos" pelo jornal, eles também ganham pouca visibilidade nas páginas.

2 Os limites de espaço entre pequeno médio e grande são definidos a partir de uma fórmula, chamada de Fórmula de Sturges, que distribui os casos em amplitudes iguais. Exemplo: se menor texto tem $10 \mathrm{~cm} 2$ e o maior $1000 \mathrm{~cm} 2$, a fórmula trabalha com a amplitude de 990 $\mathrm{cm} 2$ e divide em três partes com mesmas amplitudes $(330 \mathrm{~cm} 2)$ cada um. 
Tabela 6 - Tamanho dos textos (de acordo com Sturges)

\begin{tabular}{|l|c|c|c|c|}
\hline \multicolumn{5}{|c}{ Tamanho em faixas x Tema Geral } \\
\hline Tema & Baixo & Médio & Alto & Total \\
\hline $\begin{array}{l}\text { Políticas públicas } \\
\text { em meio ambiente }\end{array}$ & 198 & 34 & 6 & 238 \\
\cline { 2 - 5 } & $83,2 \%$ & $14,3 \%$ & $2,5 \%$ & $100,0 \%$ \\
\hline \multirow{2}{*}{ Denúncia } & 315 & 52 & 5 & 372 \\
\cline { 2 - 5 } & $84,7 \%$ & $14,0 \%$ & $1,3 \%$ & $100,0 \%$ \\
\hline \multirow{2}{*}{$\begin{array}{l}\text { Resultado de } \\
\text { pesquisas }\end{array}$} & 74 & 15 & 4 & 93 \\
\hline \multirow{2}{*}{ Eventos } & $79,6 \%$ & $16,1 \%$ & $4,3 \%$ & $100,0 \%$ \\
\hline \multirow{2}{*}{ Educação ambiental } & 56 & 5 & 0 & 61 \\
\cline { 2 - 5 } & $91,8 \%$ & $8,2 \%$ &, $0 \%$ & $100,0 \%$ \\
\hline \multirow{2}{*}{ Outro } & 14 & 1 & 0 & 15 \\
\cline { 2 - 5 } & $93,3 \%$ & $6,7 \%$ &, $0 \%$ & $100,0 \%$ \\
\hline Total & 4 & 0 & 0 & 4 \\
\hline & $64,0 \%$ &, $0 \%$ &, $0 \%$ & $100,0 \%$ \\
\hline
\end{tabular}

Fonte: Autores

Os valores maiores estão todos na categoria 'baixo', pois esta engloba mais de $84 \%$ dos textos pesquisados na amostra e aparece sempre em número acima dos demais. Dessa forma, analisaremos a Tabela 4 fazendo a relação com o valor médio e o de cada um dos temas. A média do tamanho 'baixo' é de $84,4 \%$ e apenas 'discussão/políticas públicas' e 'resultados de pesquisa' estão abaixo dessa média, com $83,2 \%$ e $79,6 \%$. Isso significa que as demais categorias apresentam maior número de textos de tamanho ‘baixo' do que a média geral, centrando a produção em textos curtos e mais uma vez mostrando como a produção na área de meio ambiente é fragmentada e pouco aprofundada devido ao pouco espaço destinado a ela. Na categoria 'educação ambiental', por exemplo, 93,\% dos textos estão na categoria 'baixo', um valor bem acima da média, que é de $84,4 \%$ na categoria. Textos sobre eventos também ultrapassam a média, com 93,3\%. Isso significa que a maior parte deles tem tamanho pequeno e isso pode ser explicado pelo fato de que as notícias sobre isso, geralmente são notas de divulgação e não de cobertura do evento. Já quando falamos de 
'educação ambiental', um tema que não é tão factual e poderia receber uma melhor apuração, percebe-se que isso não acontece e os textos estão concentrados na categoria 'baixo'.

Na categoria 'grande', apenas resultados de pesquisa, com $4,3 \%$, e discussão/políticas públicas, com $2,5 \%$, estão acima da média, que é $1,9 \%$. Isso significa que estes assuntos têm uma incidência maior de textos grandes. Essas duas categorias também têm grande número de textos 'médios'. A média é $13,7 \%$, mas apresentam $16,1 \%$ e $14,3 \%$ dos textos como sendo de tamanho 'médio'. Nessa categoria, 'denúncia' também está acima, mas com uma diferença menor, apresentando $14 \%$ dos textos na categoria 'tamanho médio'.

Na Tabela 7 são apresentados os números de entradas em cada editoria, o que ajuda a mostrar onde o tema aparece distribuído no jornal e também apresenta indícios do enfoque que o assunto recebeu e como ele vai ser debatido pelos atores sociais na medida que a agenda da mídia constrói a agenda pública.

\section{Tabela 7 - Presença dos textos nas editorias}

\begin{tabular}{|l|c|c|}
\hline Editoria & № de entradas & $\%$ \\
\hline Agrofolha & 17 & 2,2 \\
\hline Atmosfera & 10 & 1,3 \\
\hline Brasil & 59 & 7,5 \\
\hline Capa & 65 & 8,3 \\
\hline Ciência & 180 & 22,9 \\
\hline Cotidiano & 316 & 40,3 \\
\hline Dinheiro & 46 & 5,9 \\
\hline Especial & 1 &, 1 \\
\hline Especial Eco-92 & 10 & 1,3 \\
\hline Esportes & 2 &, 3 \\
\hline FolhaTeen & 3 &, 4 \\
\hline Mundo & 32 & 4,1 \\
\hline Opinião & 41 & 5,2 \\
\hline Turismo & 1 & 100,0 \\
\hline Total & 783 & \\
\hline
\end{tabular}

Fonte: Autores 
Percebe-se que as editorias Cotidiano e Ciência são as que apresentam maior número de entradas. As matérias se concentram nessas duas (totalizando 63,2\% das entradas) e as outras dão menos visibilidade ao tema, como é o caso das editorias Dinheiro, Brasil e Mundo (a princípio o tema não é abordado com enfoque econômico e político). Em alguns casos, como durante a ECO-92, foi criada uma editoria especial para fazer a cobertura do evento e que teve duração apenas de alguns dias, enquanto ocorria a Conferência. Essa abertura de espaço demonstra visibilidade ao assunto, porém fica restrita apenas ao evento e não abrange o tema meio ambiente como um todo, ou seja, não há uma editoria específica para tratar do assunto, por isso ele aparece disperso nas outras.

Para ajudar a entender como os assuntos aparecem no jornal, a terceira e última variável, mostra o assunto específico de cada texto coletado. Como o espaço ficava aberto para escrever, no final da pesquisa, contabilizaram-se 68 assuntos específicos, como, por exemplo: desmatamento, enchente, novas tecnologias, transgênico, energia, entre outros. Como a Tabela 8 apresenta muitas categorias, apresentaremos abaixo apenas alguns exemplos que possam dar um panorama de como há disparidade entre um assunto e outro durante o período observado.

TABELA 8 - Frequência dos temas específicos das matérias

\begin{tabular}{|l|c|c|c|c|c|}
\hline Tema & Frequência & $\%$ & Tema & Frequência & $\%$ \\
\hline Enchente & 112 & 14,3 & Legislação Amb. & 13 & 1,7 \\
\hline Desmatamento & 52 & 6,6 & Reciclagem & 16 & 2,0 \\
\hline Poluição do ar & 45 & 5,7 & Efeito estufa & 14 & 1,8 \\
\hline Transgênico & 35 & 4,5 & Biopirataria & 6 & 0,8 \\
\hline Biodiversidade & 32 & 4,1 & Reflorestamento & 6 & 0,8 \\
\hline Poluição de rio & 28 & 3,6 & Rio+5 & 6 & 0,8 \\
\hline Aquecimento Global & 25 & 3,2 & Produtos Orgânicos & 3 & 0,4 \\
\hline Preservação & 24 & 3,1 & Protocolo Do clima & 2 & 0,3 \\
\hline Mudança climática & 19 & 2,4 & Rio+10 & 2 & 0,3 \\
\hline Poluição do solo & 18 & 2,3 & Fórum da Água & 1 & 0,1 \\
\hline Biocombustível & 17 & 2,2 & Ecodesenvolvimento & 1 & 0,1 \\
\hline
\end{tabular}

Fonte: Autores 
De acordo com a tabela (Tabela 8), é possível perceber que a incidência dos temas varia muito, além do grande número de temas específicos que foram coletados (68 tipos diferentes). 0 que tem maior número de entradas é 'enchentes', com 112 textos, representando 14,3\% do total coletado. 'Desmatamento' e 'poluição do ar' ocupam o segundo e terceiro lugar, respectivamente, com 52 e 45 textos. Ao contrário destes assuntos que são encontrados em grande quantidade, há outros que apareceram apenas uma vez, como é o caso do ecodesenvolvimento. Textos relacionados a eventos, como é o caso do Fórum da Água, que ocorreu em 2003, também aparecem em pequena quantidade, pois só estão no jornal devido ao evento, diferente de enchente e desmatamento que sempre acontece em algum lugar do país, sem depender de um acontecimento produzido.

Outro ponto importante relacionado a esses temas específicos é como eles aparecem ao longo do tempo. E isso oscila bastante conforme alguns exemplos que serão apresentados nos gráficos e tabelas a seguir. Há temas que apareciam, mas só depois passaram a crescer visivelmente nas páginas do jornal; alguns que estão atrelados a eventos e aparecem apenas em determinados períodos; outros que aparecem apenas depois de certo tempo; uns apareciam e foram perdendo espaço para outros temas; os que oscilam diversas vezes, sem longos períodos de queda ou crescimento que sejam visíveis; e os que apresentam visíveis períodos de queda, pico e crescimento. Para isso serão apresentados alguns gráficos referentes aos assuntos específicos dispostos na Tabela 8 que exemplificam as diferentes variações ao longo dos 17 anos. O primeiro deles (Gráfico 2) é mostrando o desenvolvimento do tema 'aquecimento global'. 
Gráfico 2 - Variação da incidência do tema aquecimento global

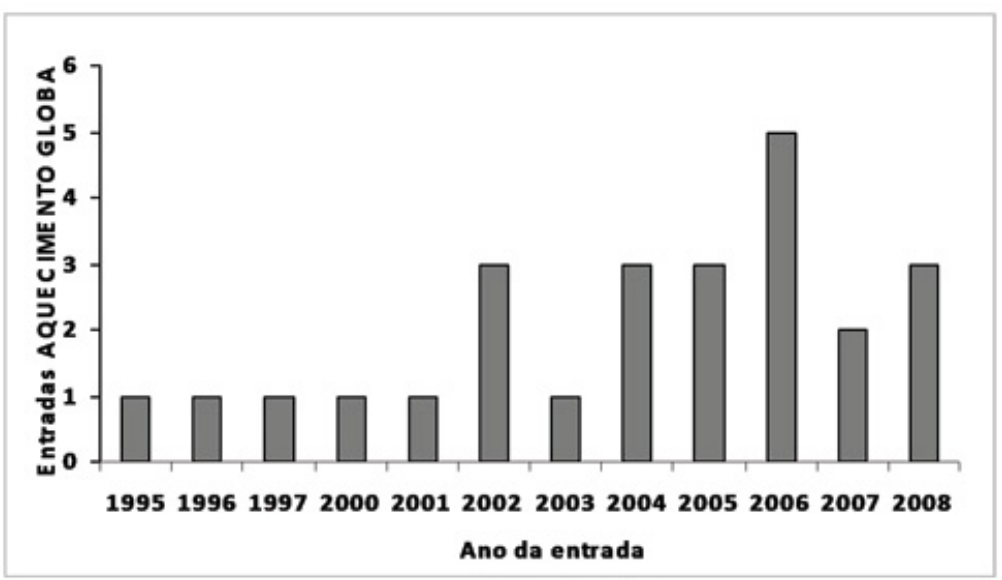

Fonte: Autores

A produção sobre esse assunto aparece com maior número de entradas nos últimos anos da análise e pequena incidência no início. Até 2000, em alguns anos analisados não foi encontrado material na amostra $(1992,1993,1994,1998,1999)$. Já a partir do ano de 2002, o tema apareceu em todos os anos. O número maior de textos foi coletado em 2006 e na maioria falavam sobre resultados de pesquisas que mostrava o aumento da temperatura da terra. Esse, portanto é um exemplo de tema que ganha visibilidade a partir de um tempo, apesar de já estar presente desde o início do período analisado. O tema 'biodiversidade', apresentado no gráfico seguinte, Gráfico 3, também tem semelhança na distribuição do tema ao longo do tempo, mas apresenta-se mais oscilante. 
Gráfico 3 - Incidência do tema biodiversidade de 1992 a 2008

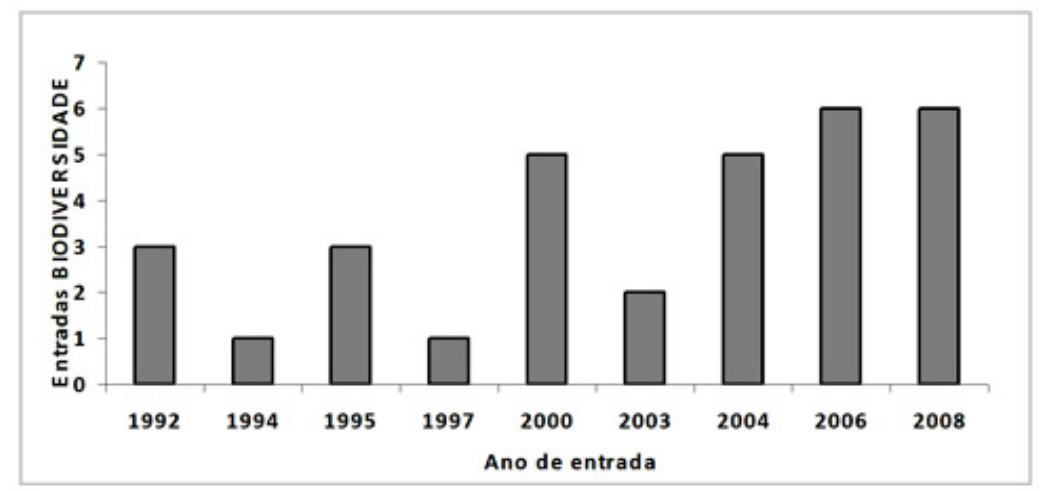

Fonte: Autores

O Gráfico 3 mostra que o tema biodiversidade, apesar de estar presente já em 1992, apresenta períodos de pico em 2000, 2004, 2006 e 2008, porém em período intermediários (2001, 2002, $2005,2007)$ não há sequer incidência do tema. Isso demonstra que o tema, apesar dos períodos de pico, não está sempre presente no jornal, pois apresenta grandes oscilações. Enquanto, em 2004, foram catalogadas cinco entradas sobre o assunto, no ano seguinte, em 2005, não houve nenhuma entrada. Mesmo com a grande quantidade de notícias no final do período analisado, não é possível dizer que houve crescimento, já que os anos que intercalam os períodos de pico não apresentaram nenhuma matéria na amostra coletada. Esse tema exemplifica os casos que oscilam bastante durante o tempo pesquisado. O Gráfico 4 mostra outro exemplo de assunto que aparece apenas a partir de um determinado tempo na pauta do jornal. 
Gráfico 4 - Distribuição do tema "transgênico" ao longo do período

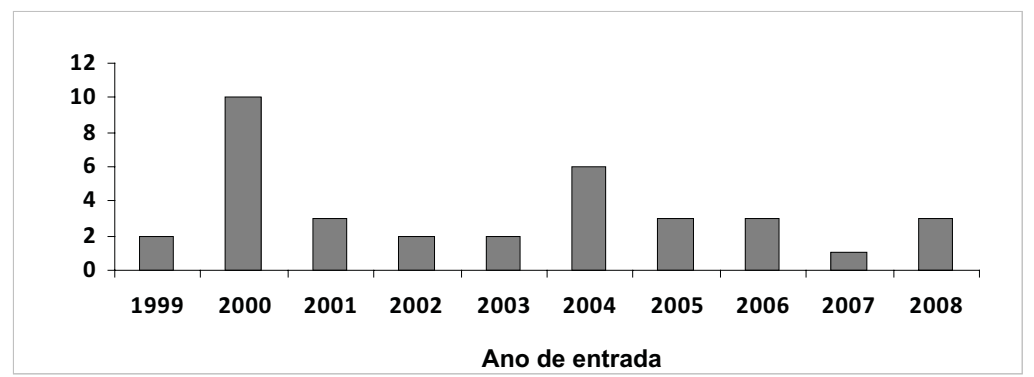

Fonte: Autores

O tema 'transgênico', diferente dos demais analisados, só aparece a partir de 1999. Isso acontece, pois anterior ao período os produtos geneticamente modificados não geravam discussão na sociedade. A partir do momento que eles entraram na agenda pública, os veículos passam a pautar o tema. Segundo Sampaio (2002), somente a partir de 1998 foi autorizada a plantação de transgênico no Brasil, mas o uso foi suspenso logo em seguida, o que provocou diversas discussões e a criação de leis que dificultam a experimentação em diversos estados. Como o assunto tornou-se polêmico, isso se refletiu na produção feita pelo jornal. 'Encontro discutirá OGMs' (26/02/2000, Mundo 1.3) e 'Transgênico sofre derrota' (14/08/199, capa) mostram que a discussão do tema pela sociedade começou a ser pautada pelos veículos de comunicação a partir da produção que começa a aparecer a partir de 1999.

Os dois últimos exemplos ajudam a mostrar como os temas não são sempre os mesmos e vão mudando com o tempo. E conforme aumenta o número de acontecimentos na sociedade, consequientemente eles aparecem mais no jornal. Foi o que aconteceu com os transgênicos e biocombustível, pois foram se tornando mais presentes no dia-a-dia e também no jornal. 
Gráfico 5 - Incidência do tema 'desmatamento' no período de análise.



Fonte: Autores

O 'desmatamento' exemplifica os temas que não são regulares e apresentam períodos de queda, pico e crescimento ao longo de todo o período. Por meio do Gráfico 5 é possível perceber que os anos de 1992, 2005 e 2008 podem ser considerados períodos de pico na cobertura sobre desmatamento. Já 1998 a 2000 mostram o crescimento e 2000 a 2003 a queda. De 2004 a 2008, o tema apresenta oscilações maiores, devido aos dois períodos de pico (2005 e 2008). Em 2005, o pico pode ser explicado pela incidência de textos sobre novos dados sobre o desmatamento e as discussões sobre a relação com a agricultura e pecuária. Em 2008, aparecem diversas notícias sobre denúncias de desmatamento ilegal no Mato Grosso e região Sudeste. Dessa forma, o assunto aparece em todo o período, mas em alguns momentos perde espaço para outras temáticas. Essa oscilação mostra que o tema não é, de fato, permanente no jornal, mas ele depende de acontecimentos para introduzir a cobertura.

Por meio desses gráficos conclui-se que os temas não estão presentes durante todo o período de análise. Enquanto alguns perdem espaço, outros passam a ocupá-lo e pautar o jornal. Como o período de análise é bastante longo fica visível como os assuntos 
não permanecem estáveis ao longo do tempo. A análise permite observar que na medida em que os temas passam a ser discutidos pela sociedade e pelos governos, os veículos passam a incorporá-los na produção.

Os dados recolhidos na amostra ajudam a entender como um tema acaba ganhando mais espaço que outro, devido a seus valores notícia: impacto, novidade, factualidade, tamanho etc. Isso se verifica quando observamos que os temas relacionados à educação ambiental, por exemplo, aparecem em pequena quantidade se relacionado com outros temas. As notícias de denúncia, apesar de envolverem empresas, governos e entidades passam a ter mais visibilidade, na medida em que chamam a atenção, causam mais impacto na sociedade e instigam o leitor a comprar o jornal. Os dados também revelam que denúncia é o tema que mais aparece nas capas. Essa escolha do veículo se dá pelos valores notícias atrelados ao fato.

Temas como 'reciclagem' e 'produção orgânica', aparecem 16 e três vezes, respectivamente. Mesmo sendo assuntos que frequientemente são pautas de eventos, ocupam espaço nas discussões da sociedade e são importantes para a preservação do meio ambiente, não ganham tanto espaço no jornal. Apesar de propiciarem informação ao leitor, as notícias muitas vezes não contêm informação que causa impacto na sociedade como, por exemplo, informar que as enchentes causam mortes, que toneladas de peixes morrem por poluição, que a temperatura da terra vai aumentar e causar sérios problemas a saúde humana.

Essa discussão proposta não significa que estes fatos (desastres) não devem ser noticiados, pelo contrário, a população deve ser informada, já que os meios de comunicação fazem o papel de levar à 'realidade' distante para perto de seus leitores. O jornalismo ambiental é considerado por Villar (1997) uma das especializações do jornalismo e dessa forma a cobertura não deveria ficar restrita apenas ao factual. Mesmo sendo um veículo diário, seria necessário contextualizar o fato e apontar possíveis soluções e consequiências, o que englobaria matérias de educação ambiental, 
por exemplo. Se houve essa relação entre os temas, os gráficos não apresentariam tanta disparidade entre um assunto e outro, como é o caso do Gráfico 1, acima, que mostra o espaço que cada tema obteve no jornal durante o período.

\section{Considerações Finais}

O primeiro aspecto a ser ressaltado é que os temas relacionados ao meio ambiente não possuem o mesmo espaço no jornal e essa diferença pode ser refletida posteriormente naquilo que a sociedade discutirá sobre o tema meio ambiente. Ou seja, os temas selecionados pelo jornal são os que serão prioritariamente discutidos na sociedade e auxiliará na formação da opinião pública, partindo do princípio de que os meios de comunicação se configuram como importantes na formação da agenda pública por estarem sempre presente no dia-a-dia da sociedade. Isso se verifica quando 'denúncia' e 'políticas/discussões públicas' tem um número bastante elevado em relação aos demais, tanto na quantidade de entradas coletadas quanto no espaço utilizado por cada um. Já 'educação ambiental' apresentou um número pequeno de textos jornalísticos sobre o assunto e é quase insignificante perto do número total catalogado. Das 783 entradas sobre meio ambiente que faziam parte da amostra, apenas 15 abordavam o tema 'educação ambiental'. Dessa forma, é possível perceber que a abordagem feita pelo jornal fica restrita a apenas alguns assuntos, enquanto outros são quase invisíveis o que estaria se refletindo na agenda pública, pois o jornal não trabalha de forma equilibrada com todos os temas sobre meio ambiente. Esse fato pode estar relacionado com os critérios de noticiabilidade, pois o tema denúncia tem muito mais impacto do que o tema "educação ambiental". A partir desses dados, é possível dizer que o tema educação ambiental só chega ao debate público por meio dos outros atores (ONGs, ambientalistas e especialistas) e não da mídia. Ressalta-se que falamos apenas de um jornal, a Folha de São Paulo, mas que este é um jornal de circulação nacional e com maior tiragem segundo os dados do site do jornal na internet, o que o torna um meio importante de 
difusão de informação por atingir um grande número de pessoas e em muitos casos, ser a fonte de informação de veículos menores, como o rádio, que atinge um público maior do que o próprio jornal.

Por meio dos gráficos que mostraram a incidência dos temas específicos ao longo do tempo, percebe-se que não são sempre os mesmos, pois alguns aparecem (como os transgênicos) e outros perdem visibilidade (como enchentes e a Eco-92) com o passar dos anos. O que ajuda a explicar uma afirmação de Franciscato (2002) ao falar dos valores-notícias e critérios de noticiabilidade internos da redação: "a notícia pode ser entendida como um momento de atuação do jornalista na produção de uma singular combinação de qualidades de um fenômeno em um tempo e espaço concretos". Ou seja, o que é notícia em um determinado tempo não o é em outro espaço de tempo, o que está relacionado com os acontecimentos factuais (enchentes) e os eventos que só ganham importância naquele período em que acontecem. Observando os dados sobre o número de entradas e espaço utilizado pelos temas (denúncia, resultado de pesquisa etc.) pode-se dizer que o jornal prioriza notícias de maior impacto, que seriam as denúncias e catástrofes, por exemplo. As matérias de educação ambiental, que ajudariam a contextualizar as mais factuais quase nunca aparecem. Dessa forma, o jornal estaria perdendo o seu papel, que segundo Aruguete (2005) seria de informar a população, já que em muitos casos é o principal ou até o único meio de informação da sociedade sobre o assunto, já que os outros atores sociais possuem um poder menor de abrangência do que a mídia.

Outra informação importante é que, de acordo com os dados recolhidos pela amostra no Jornal Folha de São Paulo, as conferências realizadas pela $\mathrm{ONU}$ não foram necessariamente o que desencadeou a discussão sobre os 'temas ambientais' no jornal. Os temas abordados em cada um dos eventos (desenvolvimento sustentável e mudanças climáticas) não apresentam elevação após os eventos. Essa informação contesta, em partes, a hipótese de que as conferências de 1992 e 2002 contribuíram para o aumento 
do número de textos no jornal a partir dos assuntos discutidos no evento. Em 1992, de fato, houve um número de matérias bastante acima dos demais, mas em 2002 o número apresenta-se menor que o ano anterior. Pode-se concluir então que apenas um dos eventos influenciou na produção do jornal, e isso se deve muito a proximidade, já que o evento de 1992 aconteceu no Brasil. Mas deve-se observar que os eventos contribuíram apenas para a produção das notícias sobre ele naquele período específico, mas que a mídia não tomou como tema permanente no jornal os assuntos discutidos nas conferências.

Percebe-se que, mesmo que o tema meio ambiente não possua um espaço próprio no jornal, cada tema específico tem relação com uma editoria, o que contribui para direcionar o texto jornalístico dando a ele um enfoque econômico, político, etc.. Um último fator importante a ser ressaltado é que os temas específicos das notícias variam bastante com o tempo, já que a análise aborda um período longo. É o caso de temas que surgem durante o período, outros que perdem espaço e outros que possuem períodos de queda e elevação, etc. O que estaria relacionado com os fatos cotidianos e os critérios de noticiabilidade. E, apesar do número total de entradas não oscilar muito durante o período, os temas específicos ganham e perdem espaço, ou seja, um ocupa o espaço do outro.

Além disso, é importante observar que apesar do tema aparecer durante todo o período, não teve aumento significativo e nem aparece em grande número, se compararmos com outros temas, por exemplo, que por terem uma editoria específica, possuem maior espaço no jornal como é o caso de economia, esportes, entre outros. A partir dos resultados obtidos nessa pesquisa é possível contestar a informação da Folha de São Paulo de fazer debate público sobre os assuntos importantes na sociedade. No caso do meio ambiente apesar do tema aparecer no jornal, e de alguma forma haver esse debate, ele não se apresenta plural e se dá apenas pelos acontecimentos factuais, o que faz não ser permanente (o espaço destinado ao tema oscila durante o período). 
De acordo com a análise, a promessa do jornal não se cumpre por diversos fatores, como a atenção para eventos factuais, o que é evidente na cobertura oscilante ao longo do tempo, já que ainda é dependente de fatos isolados para ganhar espaço no jornal; e não propõe textos com caráter mais contextual e de conscientização do leitor (educação ambiental).

Recebido em: 27.04.2010

Aprovado em: 5.01.2011

\section{Referências}

ARRUGUETE, N. Los medios de comunicación y la formación de la agenda pública. Verso e Reverso - revista de comunicação. Unisinos, n 41, Ano XIX, 2005/2.

BAUER, M.W. Análise de conteúdo clássica: uma revisão. In: BAUER, M.W. \& GASKELL, G. (org.). Pesquisa qualitativa com texto, imagem e som: um manual prático. Petrópolis: Vozes, 2002.

BLANCO, P.S. Opinión pública y democracia deliberativa:médios, sondeos y urnas. Madri: ISTMO, 2000.

FRANCISCATO, C.E. Limites teóricos e metodológicos nos estudos sobre a noticiabilidade. Texto apresentado no $11^{\circ}$ Encontro Anual da Associação dos Programas de Pós-Graduação em Comunicação/ COMPÓS. Rio de Janeiro-RJ, 2002.

FUKS, M. Arenas de ação e debate públicos: conflitos ambientais e a emergência do meio ambiente enquanto problema social no Rio de Janeiro. Dados. Rio de Janeiro, vol. 41, n. 1, 1998.

HABERMAS, J. Political Communication in mídia Society: Does Democracy still enjoy na epistemic dimension? The impactof Normative Theory on Empirical Research. Communication Theory, n 16, 2006, p. 411-426.

KIOUSIS, S. \& McCOMBS, M. Agenda-setting effects and attitude strength. Communication Research, v. 31, no 1, 2004 (p. 36 a 57). 
MAIA, R.C. Visibilidade e "accountability": o evento do ônibus 174. Trabalho apresentado ao XIII Encontro Anual da Associação Nacional dos Programas de Pós-Graduação em Comunicação (COMPÓS), São Bernardo do Campo/SP, 22 a 25 de junho de 2004.

McCOMBS, M. A Teoria da agenda: a mídia e a opinião pública. Petrópolis: Vozes, 2009.

McCOMBS, M. \& SHAW, D. The Agenda Setting Functions of Mass Media. The Public Opinion Quarterly. v. 36, no 2, 1972 (p. 176 a 187).

SANTIAGO, D. O debate público produzido pela mídia e a conservação da eficácia da lei. Trabalho apresentado no Congresso Internacional de Legística - Qualidade da lei e desenvolvimento, 2007.

SANTOS, R. Jornalistas e fontes de informação: a sua relação na perspectiva da sociologia do jornalismo. Coimbra: Minerva, 2003.

SCHMIDT, S. Páginas verdes - A presença da emoção no jornalismo especializado em meio ambiente: uma análise da seção de entrevistas pingue-pongue da revista Ecologia \& Desenvolvimento. (Dissertação de Mestrado). Universidade Federal do Rio Grande do Sul, 2005.

TOSI, J. \& VILLAR, R. Jornalismo Ambiental: onde estão as faculdades de comunicação? Revista Ecos. Pelotas, n.19, Jan. 2001.

\begin{abstract}
The debate on environment in the newspaper Folha de Sao Paulo from 1992 to 2008

The environmental theme entered the public debate from the moment that the problems caused by human actions on nature became the subject of events and conferences. It's when environmental movements emerge by persecuting the target of defending this cause. Thus, the subject also happened to be recurrent in the media, especially since the late twentieth century, becoming of public interest in the extent that it realized the importance of the environment in society. This article aims to analyze how the environmental issue is approached by the newspaper Folha de São Paulo from 1992 to 2008, in an attempt to observe the position of the media in public debate on this subject.
\end{abstract}

Keywords: public debate, environment, Folha de São Paulo. 